\title{
Transfer of Hands-on Skills in the Teaching and Learning of Civil Technology Subjects in South African Schools: A Case of Three Technical Schools in the Eastern Cape Province, South Africa
}

\author{
Maeko Mogale Simon Albert ${ }^{1 *}$, Moses Makgato ${ }^{2}$
}

${ }^{1}$ School of Education, Durban University of Technology, SOUTH AFRICA

${ }^{2}$ Department of Educational Studies, Tshwane University of Technology, SOUTH AFRICA

*Corresponding Author: maekos@dut.ac.za

Citation: Albert, M. M. S., \& Makgato, M (2020). Transfer of Hands-on Skills in the Teaching and Learning of Civil Technology Subjects in South African Schools: A Case of Three Technical Schools in the Eastern Cape Province, South Africa. Mediterranean Journal of Social \& Behavioral Research, 4(3), 47-52. https://doi.org/10.30935/mjosbr/9601

\begin{abstract}
The integration of the theory and practical components in the teaching and learning of the Civil Technology subject is requisite. This is to ensure the transfer of the much needed hands-on skills in a country desperate for technological emancipation. It is regrettable that some South African schools offering the Civil Technology subject have been caught wanting in this aspect. This paper therefore investigate the challenges of transferring Civil Technology hands-on skills and how these challenges can be resolved in order to move the subject forward. The study was conducted on 41 Grade 12 learners and 3 teachers from the three senior secondary schools in the Eastern Cape Province. Classroom observations and interviews were conducted with the purpose of ascertaining how hands-on activities were conducted in the workshop. It was established that the teaching of the subject has become too theoretical to the detriment of the psychomotor abilities.
\end{abstract}

Keywords: hands-on skills, civil technology, practical skills, Eastern Cape, theory and practical

Received: 25 Jun. $2020 \bullet$ Revised: 26 Sep. $2020 \bullet$ Accepted: 14 Nov. 2020

\section{INTRODUCTION AND BACKGROUND}

The Grade 10-12 Civil Technology curriculum in South African schools' policy prescribes the subject to infuse both the theoretical and practical aspect. The policy document for the subject advocates 4 contact periods a week, where $2 \frac{1}{2}$ hours should be theory and $1 \frac{1}{2}$ practical (Department of Basic Education, DBE, 2011:15). Therefore, the need to infuse the practical into theory remains key. This is because Technology education curriculum should be designed to train individuals to become craftsmen, technicians and technologist in different occupational areas (Rufai, BinMusta'amal, Kamin \& Saud 2013:74). Umar \& Ma 'aji (2010:65) contest that this aspect of the curriculum can only be implemented where facilities in the workshop are adequate and relevant. This should be vital to create school graduates who will be able to earn an income in a country where unemployment rate is sitting at 24,10\% (Trading Economics, 2014). School workshops offer opportunities for practical training of learners in the acquisition of skills in different trade areas (Rufai et al, 2013:75). Skills training in technology education is regarded by most countries as the pivot on which their development revolves because of the benefits stored in it such as job creation, entrepreneur skills acquisition and poverty alleviation among others (Chinyere, 2010:81). According to
Uwaifo (2010:40), technology education has more direct impact on national welfare more than any other profession. Thus, it is no exaggeration to assert that technology education is the bedrock upon which advance nations are based (Kennedy, 2011:46). Furthermore, Kennedy (2011:53) maintains that the training received by learners in technology education these days is too theoretical to the detriment of the practical aspects of the lessons. Sadly, Chinyere (2010:82) discovered that what is available in schools for technology skills training is a situation of inadequate training facilities in the form of materials, tools, equipment, workshops and inappropriate delivery method. The teaching and learning of Civil Technology in some South African schools currently is of a serious concern as learners graduate Grade 12 without requisite basic hands-on skills.

Hands- on skills are found in many subject areas of technology education such as Electrical Technology, Mechanical Technology and Civil Technology (Kennedy, 2011:54). The use of projects like mouldings, simple construction of wood joints, casting of concrete foundation, laying of blocks/bricks, floor tiling, etc. becomes necessary with the purpose of providing an opportunity for hands-on practical in the context that is meaningful to learners (Kennedy, 2011:51). In Civil Technology, through the integrated completion of theoretical work and the practical assessment tasks (PAT) hands-on skills in respect of safe working practices; good housekeeping; first aid practices; erection of

( 2020 by the authors; licensee MJOSBR by Bastas, Cyprus. This article is an open access article distributed under the terms and conditions of the Creative Commons Attribution License (http://creativecommons.org/licenses/by/4.0/). 
structures; working with accurate measurements; and workshop practice will be developed (DBE, 2011:9). The training in this regard can only be practically conceivable if there are materials and equipment for leaners to manipulate.

\section{THE SIGNIFICANCE OF PRACTICAL LESSONS IN CIVIL TECHNOLOGY}

Workshop training offers learners an opportunity to manipulate equipment and to work with other materials as well. This in turn helps learners to make the connection between real life situations and the classroom instructions. The technological education is considered as a formal type of education for providing suitable skills, practical skills and scientific knowledge to make learners ready for joining labour market (Ahmed, 2011:22). The concept of practical lessons in technology education is for the transfer of skills training like hands-skills. Skill training is regarded by most countries as the pivot on which their development revolves because of the blessings or benefits stored in it such as; empowerment, job creation/ entrepreneurial skill acquisition and poverty alleviation among others (Chinyere, 2010:81). Like any science-based subject, Civil Technology should integrate both the theoretical and practical component for practical to complement theory. Ideally the workshop in schools should provide equipment and material in order for learners to acquire practical hands-on skills (Umar \& Ma'aji, 2010:65). Skill acquisition involves the mastery of practical skills and knowledge in any technology field of study and this is done through training, teaching, practical experiences and on-the- job training (Bayode and Uzoka, 2010:118). The concept of skill acquisition in technology education is geared towards empowering youths and adults alike with requisite skills, so that the dreams of gainful selfemployment, job creation and improvement of life can be achieved (Ofoye and Asarah, 2010:139).

Chinyere (2010:84) posits that practical work constitutes an essential component of technology education. The use of practical work is to illustrate theory, contest Johnstone and Al-Shuaili (2001:42). It should be noted that theoretical understanding is gained relatively slowly through practical work (Reid and Shah, 2007:175). This simply means that learners need practical work to make sense of theory. In Civil Technology, the use of practical work is key to help learners understand theoretical concepts. This is in line with Mewis (2011:44) assertion that practical work helps to support learning and also illustrate key concepts. In the same vein, Seiter (2009:422) recommended that for learners to develop manual skills and cognitive reasoning in technology education, they must be given access to workshops which will allow all possible methods of working with materials and equipment. The teaching and learning of both theory and practical are key components in the handling of Civil Technology subject and should one of these two key components be removed; the subject will seriously be handicapped. The consequences of this will be undesirable as learners will graduate high school half-baked in the subject.

\section{THE CHALLENGES FACING CIVIL TECHNOLOGY TEACHING AND LEARNING IN SCHOOLS}

All technology-based subjects require more instruction and practical time than arts and science education (Boateng, 2012:110). Umunadi (2010:5) avers that schools offering technology subjects face inadequate funding and facilities, inadequate and inappropriate staffing. In the same vein, Kennedy (2010:21) declares that facilities like workshops equipment and materials are grossly inadequate in schools and therefore pose a serious challenge in the teaching and learning of technology subjects. This does not argue well for the holistic teaching and learning of the subject. In the absence of facilities like workshop and materials, the subject becomes theoretical. It should be noted that the teaching of Civil Technology, just like any practical subject is centered on the practical lessons. Reid and Shahi (2007:40) assert that to improve the teaching of practical lessons, it is necessary for students to handle laboratory equipment regularly and adequate time need to be given to students to learn techniques of using equipment and developing skills for practical. However, Moemeke (2010:95) insists that practical work as means of developing skills in creativity and mental skills have been so highly neglected in schools. In addition, (de Jager, 2011:149) posited that although practical work is extremely important in all technology education subjects, most of the schools in South Africa are under resourced and has since neglected the practical since the start of the subject due to a lack of resources. Like any technology-based subject, the development of both creative and mental skills remains key for the successful teaching and learning of Civil Technology. Without this, the offering of the subject becomes a deception.

\section{PROBLEM STATEMENT}

Learners in some South African schools graduate Civil Technology Grade 12 class without the basic hand skills required to enter the technical world of work. This unfortunately add numbers to the already high unemployment rate in the country. The following research questions becomes key in the investigation:

1. How is the Civil Technology practical component handled in selected schools in terms of teaching and learning?

2. What is the significance of the practical aspect of the subject in relation to employment opportunities?

\section{METHODOLOGY}

The study adopted a qualitative research design in carrying out the investigation. Henning, Van Rensburg and Smit (2009:3) describe a qualitative study as a study which aims for depth than quantity of understanding. Therefore, the study made use of structured interviews as well as classroom observation to conduct. The interviews were commonly structured and standardized for all the three sample schools. All the three teachers were interviewed in their respective schools. Observations were also carried out as another method to get first-hand information and to adduce more evidence on how Civil Technology practical activities are being conducted. The observation schedule was adapted from Differentiated Classroom Observation Scale Protocol 
(Grant, Stronge and Popp, 2008:70). The researcher spent the whole day in each of the three selected schools observing how the practical component of the subject was being handled whiles activities were underway in schools. The interview data was first analyzed by transcribing. Each transcription was considered with the aim of identifying key issues. Descriptions were then formulated from the key issues identified as relevant to the study and coded. Themes, which are a pattern of answers emerging consistently and more often to highlight a common issue, were created, and then categorized into headings and constructively narrated with the support of verbatim.

Data derived from observation was analyzed descriptively per item that was reflected in the schedule. Each item that the researcher had on the observation schedule was analyzed per school with the purpose of getting a connection of the activities in the Civil Technology workshops in the three schools. The analyses were mainly done by paying attention to all the items in the observation schedule and themes were developed from the field notes obtained from what the researcher observed from the three selected schools. The results were narrated to give a true reflection of what was observed.

\section{POPULATION AN SAMPLING}

A "population" consists of all the subjects you want to study (Yount, 2006:2). The population in this study comprised of three schools offering Civil Technology in the Eastern Cape Province. These schools are situated in three different districts around the Eastern Cape Province. The researcher selected these schools on the basis of their immediate vicinity and accessibility. Notably, the Eastern Cape Province is too rural and most villages have bad roads, which make accessibility difficult.

Dasmani (2010:62) denotes that the importance of samples lies in the accuracy with which they represent or mirror the target population. This study employed the judgmental /purposive sampling technique. All the Grade 12 learners together with their three educators from the three selected schools, were considered to be relevant to the study by virtue of them being involved in the teaching and learning of Civil Technology. Battaglia (2011:405) describes purposive sampling as a non-probability sampling method aimed at producing a sample that can be considered "representative" of the population. In the three districts, the researcher selected one school in each as his sampling technique totaling three in numbers. The respondents consisted of an easily manageable number of 41 learners in total combined from the three schools, with 25 boys and 16 girls.

\section{RESULTS AND DISCUSSION}

\section{Interviews with Civil Technology Learners}

\section{I know all the tools in the practical workshop and how to use them}

Three-quarters of the respondents said they do know most of the tools theoretically, but they have no access to them as they are not there in the workshop. The respondents said they cannot use most of the tools as some of the tools are also not in a good condition. Notably, the non-usage of tools in workshops is a blow to learners' acquisition of skills as tools are critical in the learners' everyday work in the workshop. This unpleasant response from Grade 12 learners, which is the exit point at schools is outrageous for a subject considered practical.

\section{State of workshops in schools}

In responding to the aspect above, the following theme was recognized consistently from the learners' responses: Not in a good condition due to lack of space, equipment and personal protective equipment (PPEs). Personal protective equipment (PPE's) can be described as the equipment worn from head to feet, in order to protect workers from injuries and contracting diseases in the workshop. The respondents argued that their practical workshops are normal class size and that they do not have much space to move around. In addition to that, the learners said their workshops are not adequately equipped and lack equipment, material and PPE's. The condition of workshops does not argue well for the safety of everybody involved, be the teachers or learners. According to the National Unions of Teachers (NUT) Health and Safety Briefing report (NUT, 2011:11), all practical activities can become hazardous in some circumstances due to factors such as, the suitability of the teaching area and non- usage of personal protective equipment.

\section{Projects in the workshop}

On the question of projects in the workshop the researcher wanted to establish how learners go about doing their practical project whenever they get a chance to do so. In response to this aspect, most of the learners said, "we are given readily made material to assemble a project". Apart from the learners receiving readily made materials, the respondents also said their Civil Technology teachers actually do the actual work for them in order to get good marks. The provision of readily made material to learners and the teachers' extensive involvement in doing projects for the learners actually denies the learners the opportunity to prepare the material on their own.

\section{Time spent in the workshop}

In responding to the above variable, all the respondents said, "we do not spend enough time in the practical workshop as practical are not allocated in the school time-table". The learners said they only go to the workshop in September to do PAT for one month because they have to get marks for practical which contributes to their final promotional mark. The learners' responses once more demonstrate how schools do not view the practical activities of the subject as critical. It must be noted that it is to the learners' advantage to spend more time in the workshop in order to learn practical skills.

\section{Results Based on the Interviews with Civil Technology Teachers}

The results of the interviews were transcribed in order to obtain the themes or pattern of all the results about what the teachers said. Below are the interview results with the Civil Technology teachers per question.

\section{The significance of workshop Practical for learners doing Civil Technology as a subject}

The Civil Technology teachers consistently acknowledged the importance of workshop practical for learners doing Civil Technology, as it is an integral part of the subject. The respondents unanimously indicated that the practical component of the subject help learners understand the theory part of the subject. One theme that consistently emerged when the teachers responded to the issue of workshop practical is that "for learners to make sense of theory, they have to do practical in the form of projects which will in turn help them to get employed or become self-employed". The respondents are of the view that learners should be able to become self-employed and create jobs on completion of their 
Grade 12 without any further training. However, teachers felt that the current training learners are exposed to do not offer them such opportunities.

The subject teacher from one school said "for learners to make sense of the theory part, they have to go to the practical workshop to put what they have just learned into practice. Some of the learners who went through my hands at the school during the apartheid era are self-employed and make a living without any further training". The responses from the Civil Technology teachers above attest to assert the view that Civil Technology subject cannot be taught without the practical component. It is from this perspective that practical activities need to be adequately taught for learners to make sense of the theoretical aspect of the subject.

\section{The state of the workshop}

The interviewees said that "workshops are not in a good condition and are in an appalling state which is a far cry from what the workshops should be ideally". These teachers said that the acquisition of skills without properly equipped workshops is impossible. Furthermore, the interviewees stated that they are forced to spend most of the time teaching theory which does not augur well for a practical subject like Civil Technology.

\section{Teacher A from School A said the following:}

"We do not have enough material for learners to manipulate. For us to have material for the practical projects we go beg the private sector to give us what they have discarded as waste or recycling material. I can say that the only time they have the material for the practical is when learners are expected to start with their PAT".

Teacher B from School B said the following:

"The learners do not have enough material to work with all the time. We do ask learners sometimes to bring their own material for practical projects and we also improvise as the school by levying the parents and top up the levy with school fees".

Based on the responses above, it can be asserted that when learners get the opportunity to do practicals in the workshop, they do not get the feeling of using real materials. The waste material learners receive from private sector does not expose the learners to the real world.

\section{Learners' preparation of projects}

The researcher wanted to establish how learners prepare their material whenever they get a chance to work in the workshop. There was only one theme obtained from response by the teachers, that teachers help learners with their individual projects as each learner has to get a practical mark for the final examination.

Teacher B from School B in answering the question on how learners do their projects said:

"As the material arrive late, for us to complete the project and meet the deadline for PAT moderation I have to step in and help cut the material for the learners. The project we are given this year in 2012 is for an individual to complete to get the $25 \%$ practical mark. Ideally learners were supposed to start with the project from working out a cutting list for all the material required for the project, then plane and cut wood to the required sizes and assemble the parts under my supervision and guidance. The reason I step in is to help because of time constrains and for the fact that most of these learners have never been exposed to working on machinery in Grade 10-11".

Teacher $\mathrm{C}$ from School $\mathrm{C}$ responded by saying the following when asked to answer the question on how learners go about doing their projects:

"In the case of wood work project learners have to work individually to get their $25 \%$ of the practical mark. I buy the material ready for the learners to do touch ups and assemble. This is due to the fact that the workshop does not have most machinery to prepare the material for the project. Time constrains is another factor as the school always buy us the material in the fourth quarter". The responses from the teachers above are a clear indication that the focus in the workshop is to ensure that learners get marks for the practicals. The workshops get the materials towards the end of the year, when the department's officials visit the schools to assess the learner's projects for practical mark allocation. With limited time, lack of tools and equipment to prepare material for the projects in the workshop, teachers are left with no choice but to tap in or even buy readily made material in order to help learners get good practical mark.

\section{Time for starting with the practical project for Grade 12 class}

The respondents asserted in no uncertain terms that the learners only start with the practical lessons in the 4th quarter, which is around September. The teacher from School A stated that the practical was supposed to start earlier at the beginning of the year to give learners more time to practice skill. He had the following to say:

"We were supposed to start at the beginning of the year to equip learners with practical skills, but because of the lack of material we do projects in the fourth quarter when moderation is about to take place just to meet the Civil Technology curriculum requirements for PAT as opposed to skill acquisition. We rush the practical so that learners can be able to get the 25\% of the PAT. We are sent from pillar to post when we knock on provincial government doors asking about material and equipment for learners".

In a similar vein, teacher B from School B had this to say:

"The learners only get a chance to go to the practical workshop in September to prepare for PAT. Unfortunately, this is the only time the school buys us material for the practical component". These teachers' responses indicate that the three schools are only interested in the learners receiving the requisite practical mark as opposed to them acquiring requisite practical skills.

\section{Results from Observations}

The researcher also carried out classroom observation with the purpose of ascertaining the activities conducted in the workshop as measured against items listed on the classroom observation schedule. The following was observed.

\section{Availability of equipment and material}

Notably, in all the workshops in school A, B and C respectively, the availability of equipment and material is a problem. The finding from the researcher's observation is that in all the three selected schools materials like timber and safety gear is a big challenge. Though some schools have few working machinery and few tools, Personal Protective Equipment (PPE's) like safety goggles to protect the learners' and teachers' eyes from flying wood chips, dust masks to prevent inhaling of dust which might cause lung diseases, ear-drums to protect ears from getting damaged by excessive noise coming from running machinery, safety gloves to protect hands from cuts and safety clothes like boots and overalls, are short in supply. This exposes both teachers and learners to serious health hazards.

\section{Status of workshops}

The findings from the researcher's observation reveal that the state of workshops in all the three sampled schools is poor. The workshops are small in size offering no room for free movement from point A to B. This observation confirms the responses of the majority of the learners and the teacher's responses that the workshops in the three sampled schools are in a poor condition. Most of the machinery is broken and therefore remain dysfunctional. 


\section{Safety procedures}

The workshop can be a dangerous place to work in as it contains sharp objects and dangerous machinery. With regard to this variable, the researcher observed that in all the sample schools, safety is only considered when operating the available machinery together with the handling of tools by taking safety positions when working. This then leaves both teachers and learners exposed to health hazards emanating from saw dust and injuries from flying wooden chips. All the learners together with their teachers were seen to be working without Personal Protective Equipment. Leaners together with teachers were observed to be working in dust and noisy environment caused by machinery without PPE's. Notably, woodworking exposes workers to a variety of hazards, including kickbacks, flying wood chips, noise, wood dust and chemical hazards. Personal Protective Equipment can help protect against these hazards (NUT, 2011:17).

\section{CONCLUSIONS AND RECOMMENDATIONS}

The responses indicate that learners are not exposed to the practical activities as they should. The lack of material and equipment is central to this challenge. As indicated by both the learners and their teachers, the shortage of these basic requirements in the practical workshop impact negatively on the learners' acquisition of practical skills. The insufficient time spend in the practical workshop is a clear indication of how schools view the integration of practical lessons in the Civil Technology syllabus. The serious shortage of basics like PPE's is a serious indictment defeating the goals for effective teaching and learning of any practical based subject.

From the investigations, the study can construe the frustration from the responses of both the learners and teachers. For a country that is advocating the economic growth, this is a serious setback with reference to the learners coming from such schools in the sample study. It is therefore recommended that the National Department of Basic Education intervene to restore the dignity of the subject. This can be done by dispatching a group of experts to do needs analysis in the sampled schools and provide assistance. That should be followed by proper monitoring to ensure that the intervention is sustainable in such a way that practical are not only integrated in the time-table, but taught.

\section{REFERENCES}

Ahmed, H. A. E. (2011). Building Capacity of Teachers and Trainers in Technical and Vocational Education and Training (TVET) in Sudan: Case of Khartoum State. PhD. Dissertation, Technical University of Dresden, Germany.

Battaglia, M. P. (2011). "Nonprobability Sampling”. Encyclopedia of Survey Research Methods. Newbury Park, CA. Sage Publications.

Bayode, K. \& Uzoka, I. (2010). Constraints to skill acquisition in vocational agriculture in Educational system in Nigeria. Journal of Qualitative Education, 6(1).

Boateng, C. (2012). Restructuring Vocational and Technical Education in Ghana: The Role of Leadership Development. International Journal of Humanities and Social Science, 2(4), 108-114.
Chinyere, A. S. (2010). Skill training in Nigerian technical colleges: Benefits and Challenges. 21 August 2010 [Online]. Available from: www.wesoedu.com

Dasmani, A. (2011). Challenges facing technical institute graduates in practical skills acquisition in the Upper East Region of Ghana. AsiaPacific Journal of Cooperative Education, 12(2), 67-77.

De Jager. (2011). Latest Changes in the Technology Education Curriculum in South Africa. In K. Stables, C. Benson, \& M. de Vries, (Eds.), Perspectives on Learning in Design \& Technology Education Conference, organized by Goldsmiths, University of London, Britain: 2011.

Department of Basic Education. (2011). Curriculum Assessment Policy Statements (CAPS) - Civil Technology. Available from: www.thutong.doe.gov.za/Resourcedownload.aspx?Id=44617

Grant, L., Stronge, J. H., \& Popp, P. (2008). Case studies of Award Winning Teachers of at Risk/Highly Mobile Students.

Henning, A., Van Rensburg, W., \& Smit, B. (2009). Finding your way in qualitative research. Pretoria: Van Schaik Publishers.

Johnstone, A. H. \& Al-Shuaili, A. (2001). Learning in the laboratory; some thoughts from the literature. Journal for the Royal Society of Chemistry. 17 September.

Kennedy, O. O. (2010). Skills acquisition in Nigerian education system: problems and prospects in technical education. Journal of Qualitative Education, 6(1).

Kennedy, O. O. (2011). Philosophical and Sociological Overview of Vocational and Technical Education in Nigeria. American-Eurasian Journal of Scientific Research, 6(1). IDOSI Publications.

Kennedy, O. O. (2011). Reappraising the Work Skill Requirements for Building Technology Education in Senior Secondary School for Optimum Performance in Nigeria. European Journal of Applied Sciences, 3(2), 46-52. IDOSI Publications.

Mewis, R. (2011). Staff and student opinions of the inclusion of practical work in higher education chemistry courses in England: what are the perceived objectives and outcomes? New Directions, 7, 36-44. https://doi.org/10.11120/ndir.2011.00070036

Moemeke, C. D. (2010). Restructuring science education in Nigeria for skills acquisition and diversification: a panacea in recessing economy. Journal of Qualitative Education, 6(1).

National Unions of Teachers. (2011). Safety in practical workshops. [Online]. Available from: www.teachers.org.uk

Ofoye O. I. \& Asarah, M. (2010). Skills acquisition through fine and applied arts in Nigeria: problems and prospects. Journal of Qualitative Education, 6(1).

Reid, N. \& Shah, I. (2007). The role of laboratory work in university chemistry. The journal for The Royal Society of Chemistry, 8(2), 172185. https://doi.org/10.1039/B5RP90026C

Rufai, A., BinMusta'amal, A. H., Kamin, Y. B., \& Saud, M. S. B. (2013). Provision of Workshop Tools and Equipment: Necessity for Technical Vocational Education Graduates Skills Acquisition. 2nd International Seminar on Quality and Affordable Education.

Seiter, J. (2009). "Crafts and technology" and "technical education" in Austria. International Journal of Technology and Design Education, 19, 419. https://doi.org/10.1007/s10798-009-9096-6 
Trading Economics. (2014). South African Unemployment Rate [Online]. Available from https://tradingeconomics.com/southafrica/unemployment

Umar, I. Y., \& Ma'aji, A. S. (2010). Repositioning the Facilities in Technical College Workshops for Efficiency: A Case Study of North Central Nigeria. Journal of stem teacher education, 47(3). https://doi.org/10.30707/JSTE47.3Umar
Umunadi, K. E. (2010). Acquisition of skills and competencies by technical education teachers as instrument for national growth in Nigeria. Journal of Qualitative Education, 6(1).

Yount, R. (2006). Populations and Sampling. 